\title{
Teknik pembelajaran bahasa Inggris yang menyenangkan untuk taman kanak-kanak
}

\author{
Somariah Fitriani ${ }^{\star *}$, Hamzah Puadi llyas²
}

1 Universitas Muhammadiyah Prof. DR. HAMKA, Jakarta, Indonesia, email: somariah@uhamka.ac.id 2Universitas Muhammadiyah Prof. DR. HAMKA, Jakarta, Indonesia, email: hamzahpuadi@uhamka.ac.id *Koresponden penulis

\section{Info Artikel}

Diajukan: 08 Feb 2021

Diterima: 13 Jun 2021

Diterbitkan: 22 Jun 2021

\section{Keywords:}

learning techniques; games; songs; story telling

\section{Kata Kunci:}

teknik pembelajaran; permainan; lagu; bercerita

\section{Lisensi:}

cc-by-sa

\begin{abstract}
The variety of learning by applying teaching techniques in a fun, effective and efficient manner provides an important role in the learning process of children. Therefore, this community service activity aims to train the participants' abilities in teaching techniques that are specialized in games, songs and storytelling in English. This activity was carried out by using Google Meeting for two days. In addition, the uses of learning media and class routine activities are the goal of this community service. 18 participants participated in this activity, most of whom were kindergarten teachers. The implementation was carried out using the methods of lecturing, brainstorming and discussion, demonstration and mentoring. The results show that the participants' knowledge and understanding of the given themes increased. Participants are also able to answer several questions at the end of the session and be involved in online game activities. The results of the evaluation show that this activity is very useful and beneficial in increasing their ability to implement more varied teaching techniques that are in accordance with the abilities of kindergarten children.
\end{abstract}

Abstrak
Pembelajaran yang bervariasi dengan mengaplikasi teknik-teknik
pengajaran secara menyenangkan, efektif dan efisien memberikan
peranan penting dalam proses pembelajaran anak-anak. Oleh
karenanya, kegiatan pengabdian masyarakat yang dilakukan secara
daring dengan menggunakan Google Meeting selama dua hari
bertujuan untuk melatih kemampuan peserta dalam teknik
pembelajaran yang dikhususkan pada permainan, lagu dan bercerita
dalam bahasa Inggris. Selain itu, penggunaan media pembelajaran
dan kegiatan class routine menjadi tujuan dari pengabdian
masyarakat ini. 18 peserta berpartisipasi dalam kegiatan ini yang
umumnya adalah guru-guru taman kanak-kanak (TK). Pelaksanaan
dilakukan dengan metode ceramah, curah pendapat, diskusi, metode
demonstrasi dan metode pendampingan. Hasil menunjukkan bahwa
pengetahuan dan pemahaman peserta tentang tema yang diberikan
meningkat. Peserta juga mampu menjawab beberapa pertanyaan di
akhir sesi dan terlibat dalam kegiatan permainan yang dilakukan
secara daring. Hasil evaluasi menunjukkan bahwa kegiatan ini sangat
bermanfaat dalam meningkatkan kemampuan mereka dalam
mengimplementasikan teknik-teknik pembelajaran yang lebih
bervariatif yang sesuai dengan kemampuan anak-anak TK.




\section{PENDAHULUAN}

Mengajar anak-anak adalah pekerjaan yang benar-benar bermanfaat, bahkan merupakan pekerjaan yang paling menantang. Setiap hari aktivitas yang dilakukan membawa penemuan, pencapaian, dan kegembiraan baru bagi anak-anak dan para guru (Colker, 2008). Oleh karenanya para guru harus mampu dan mempunyai keterampilan pedagogik mengenai metode dan teknikteknik pengajaran agar tercapai pembelajaran yang efektif, efisien dan menyenangkan. Seperti pendapat yang menyatakan bahwa "Untuk membuat pembelajaran lebih bermakna, dimengerti dan bermanfaat bagi seorang peserta didik, keefektifan pengajaran yang disampaikan oleh seorang guru merupakan syarat yang sangat penting" (Barman, Bhattacharyya, \& Barman, 2015). Hal senada juga diutarakan bahwa "The success with which a teacher conducts a lesson is often thought to depend on the effectiveness with which the lesson was planned" (Richards \& Renandya, 2002). Dengan demikian, guru khususnya untuk taman kanak-kanak mempunyai peran tidak hanya sebagai pengajar namun juga sebagai fasilitator dan agen perubahan. Dengan peran tersebut, guru harus mampu melakukan pengajaran dan memberikan pendidikan yang efektif melalui pendekatan, metode dan teknik-teknik yang bervariasi agar tercapai tujuan pembelajaran.

Sebagai bahasa Internasional, penguasaan keterampilan berbahasa Inggris di abad 21 menjadi hal yang sangat penting baik bagi para guru maupun bagi anak-anak. Kesiapan dan keterampilan guru dalam menunjang pembelajaran adalah penguasaan bahasa Inggris yang mencakup empat keterampilan yaitu berbicara (speaking), mendengarkan (listening), menulis (writing), dan membaca (reading) dan tiga komponen bahasa yaitu tata bahasa (grammatical structure), pengucapan (pronunciation) dan kosakata (vocabulary). Penguasaan kosakata menjadi aspek yang utama untuk meningkatkan kemampuan semua keterampilan berbahasa. Kalimat "without grammar very little can be conveyed, without vocabulary nothing can be coveyed" yang nyatakan oleh Wilkins (1972) menekankan pentingnya penguasaan kosakata terhadap kemampuan pembelajaran bahasa. Oleh karenanya, teknik permainan, lagu dan bercerita menjadi hal utama dalam pembelajaran anak-anak untuk menguasai setidaknya keterampilan berbicara terlebih dahulu. Bakhsh (2016) menekankan pentingnya implementasi permainan kosakata dan beberapa contoh permainan lainnya yang dapat digunakan untuk mengajar kosakata kepada anak-anak. Hal ini sangat diperlukan untuk membawa perubahan pendidikan bagi anak-anak didiknya. Selain itu, penguasaan metode dan teknik-teknik pembelajaran yang bervariatif sangat menunjang proses pembelajaran agar anak-anak didik dipersiapkan untuk mampu berbahasa Inggris sejak dini. Seperti misalnya, pentingnya pembelajaran kelompok kecil untuk mempromosikan keterampilan sosial anak. Demikian pula, ketika anak-anak mengerjakan proyek dengan teman sebaya, mereka belajar bagaimana berkomunikasi satu lawan satu dengan cara menciptakan hubungan sosial yang harmonis (Alpine Montessori, 2017).

Mitra dalam program pengabdian masyarakat ini adalah Taman KanakKanak Aisyiyah 92 yang merupakan taman kanak-kanak swasta yang terletak 
di bilangan Jakarta Pusat. Berdasarkan wawancara dengan kepala sekolah, dan observasi yang dilakukan tim pengabdian masyarakat, permasalahan yang mendasar adalah kurangnya kemampuan dan keterampilan berbahasa Inggris para gurunya sehingga menjadi kendala yang cukup berarti dalam memberikan pembelajaran yang lebih bervariatif. Keterampilan berbahasa asing khususnya bahasa Inggris akan memberikan nilai tambah (added values) bagi perkembangan bahasa kedua mereka atau bahasa asing. Dengan demikian pelatihan metode dan teknik pengajaran dalam bahasa Inggris juga diperlukan dalam menambah wawasan dan keterampilan berbahasa Inggris para guru. Selain itu penguasaan terhadap media pembelajaran di masa pandemi ini juga sangat menunjang keberhasilan dalam pengajaran daring yang tidak bisa dihindarkan. Beberapa permasalahan yang dihadapi oleh para guru TK Aisyiyah 92 adalah sebagai berikut: 1) Kurangnya kemampuan para guru dalam keterampilan berbahasa Inggris; 2) Kurangnya penguasaan metode dan teknik pembelajaran berbahasa Inggris; dan 3) kurangnya penguasaan dalam pemanfaatan pembelajaran dengan teknologi.

Hasil-hasil penelitian sebelumnya mengenai teknik-teknik pembelajaran dengan menggunakan permainan, lagu dan bercerita memberikan kontribusi yang positif terhadap perkembangan bahasa anak anak. Misalnya, hasil penelitian menemukan bahwa video games dan online games mempunyai pengaruh yang signifikan terhadap kosakata anak-anak (AIShaiji, 2015; Ashraf, Ghanei, \& Salami, 2014). Hasil serupa juga menyatakan bahwa permainan meningkatkan keberhasilan anak dalam kelas English for Foreign Language (EFL) dan juga meningkatkan motivasi dan kerjasama antar anak-anak (Jassim \& Dzakiria, 2019). Teknik bercerita (story telling) juga mampu membuat anakanak mengingat banyak kata dan kalimat (Kirsch, 2012), meningkatkan motivasi dan perilaku anak-anak yang lebih kooperatif (Lee, 2012). Hasil penelitian lain menyarankan perlunya implementasi sistem multimedia berbasis Web dalam kegiatan pembelajaran bercerita di kelas yang akan bermanfaat dalam memfasilitasi keterampilan berbicara siswa. Para siswa akan dapat mengingat kosakata baru lebih baik, latihan berbicara yang lebih sering dan menjadi kompeten dalam bahasa target dan selain itu meningkatkan performa pembelajaran mereka (Hwang et al., 2014). Penelitian mengenai lagu juga membuktikan tiga hal yaitu lagu-lagu yang edukatif dapat meningkatkan pengucapan dan intonasi; akusisi tata bahasa dan kosakata dan memungkinkan siswa menjadi lebih terinformasi mengenai budaya dan tertarik terhadap budaya tersebut (Xiaomei \& Quansheng, 2018).

Berdasarkan permasalahan mitra tersebut dan hasil-hasil penelitian sebelumnya, pelatihan metode dan teknik pembelajaran bahasa Inggris sangat diperlukan untuk membantu para guru dalam meningkatkan keterampilan berbahasa mereka dan juga meningkatkan metode dan teknik pengajaran yang lebih bervariatif. Sehingga fokus pada pelatihan ini adalah pelatihan metode Total Physical Response, teknik pembelajaran dengan menggunakan permainan (games), lagu (songs) dan bercerita (story telling).

\section{METODE PELAKSANAAN}


Pelaksanaan kegiatan pengabdian masyarakat yang dilakukan selama masa pandemi Covid-19 ini berlangsung selama dua hari dari tanggal 28 hingga 29 Desember 2020 melalui Google Meeting di mana masing-masing sesi berlangsung selama 3 hingga 3,5 jam. Mitra pengabdian masyarakat adalah TK Aisyiyah 92 yang terletak di jalan Petojo Enclek, Gambir Jakarta Pusat. Selain guru-guru TK Aisyiyah 92, guru-guru dari TK lain dan peserta lainnya ikut berpartisipasi dalam kegiatan pelatihan ini, sehingga jumlah keseluruhan peserta ada 18 orang yang terdiri dari 14 peserta perempuan dan 3 peserta lakilaki.

Adapun langkah langkah dan metode yang dilaksanakan dalam pelatihan daring ini meliputi: 1) Metode ceramah (lecturing) yang dilakukan pada saat awal pelatihan dengan memberikan topik secara umum mengenai pendidikan anak usia dini (early childhood education), karakteristik anak-anak, peran guru dalam pendidikan anak usia dini, metode Total Physical Response yang mengutamakan pada gaya belajar kinestetik, teknik-teknik pembelajaran permainan, lagu dan bercerita yang sesuai untuk anak-anak usia taman kanakkanak yang menyenangkan, efektif dan efisien. Selain itu kegiatan class routine yang menekankan pada komunikasi yang sederhana dalam bahasa Inggris untuk memulai pembelajaran menjadi topik yang penting untuk disampaikan; 2) Metode brainstorming dan diskusi. Metode brainstorming ini dilakukan untuk menstimulasi peserta terhadap beberapa topik yang mungkin mereka ketahui sebelumnya dan bertujuan untuk mengetahui seberapa jauh pemahaman mereka terhadap topik atau tema-tema yang disampaikan oleh narasumber. Contohnya kami meminta peserta untuk menjawab beberapa pertanyaan, seperti peran guru dalam pendidikan anak usia dini, metode yang sesuai dengan karakteristik anak-anak dan lainnya. Kemudian metode diskusi dilakukan untuk mendiskusikan dan memberikan jawaban yang tepat mengenai topik atau tema tersebut. Hal ini penting untuk dilakukan dimana peserta diajak untuk terlibat dalam pelatihan; 3) Metode demonstrasi yang memungkinkan peserta untuk mengetahui dan mempraktekkannya secara langsung mengenai jenis permainan dengan mengunakan berbagai macam media pembelajaran, lagu dan story telling yang sesuai dengan kemampuan bahasa Inggris anakanak TK dan mudah dilakukan oleh para gurunya khususnya bagi mereka yang kemampuan bahasa Inggrisnya terbatas. Narasumber memberikan beberapa contoh permainan secara langsung dan juga mengajak peserta untuk ikut terlibat.

Selain itu, narasumber memberikan beberapa contoh teknik permainan yang sesuai melalui youtube; 4) Metode pendampingan dan konsultasi yang belum bisa dilakukan secara langsung selama masa pandemi karena pembelajaran dilakukan secara daring, tapi kami membuka konsultasi melalui telepon atau whatsApp. Beberapa peserta menanyakan tentang contoh beberapa teknik pembelajaran yang mudah dan menyenangkan setelah kegiatan pelatihan usai.

\section{HASIL DAN PEMBAHASAN}


Kegiatan pengabdian masyarakat atau juga disebut program kemitraan masyarakat (PKM) mencakup lima (5) komponen penting yaitu:

1. Pencapaian tujuan dan ketuntasan materi

Pelaksanaan kegiatan sudah sesuai dengan yang direncanakan sebelumnya dan berjalan dengan baik dan lancar tanpa gangguan yang berarti. Tujuan kegiatan juga telah tercapai dengan memberikan pelatihan yang dikhususkan pada metode dan teknik pembelajaran bahasa Inggris bagi guru-guru TK. Materi yang telah dipersiapkan sebelumnya dapat tersampaikan dengan waktu yang telah ditentukan juga. Materi yang diberikan mencakup 1) pemahaman tentang pendidikan anak usia dini, karakteristik anak-anak dan peran guru dalam pembelajaran; 2) metode dan teknik pembelajaran yang berdasarkan konsep Jack C Richard; 3) metode Total Physical response dan teknik permainan, lagu, dan bercerita; 4) media pembelajaran; dan 5) pola pembelajaran anak-anak dan kegiatan class routine.

2. Kesesuaian peserta pelatihan

Tujuan pelatihan ini ditargetkan kepada guru-guru TK yang nantinya mereka akan lebih mampu dalam memvariasikan teknik-teknik pengajaran, lebih berkreasi dan meningkatkan kemampuan berbahasa Inggris mereka. Dari 18 peserta, 14 peserta adalah guru TK, satu adalah guru SD dan tiga lainnya adalah ibu rumah tangga dan wirausaha yang mempunyai keinginan untuk mengetahui lebih banyak tentang pendidikan anak usia dini dan teknik pembelajaran agar dapat dilakukan di rumah dalam mendidik anak-anaknya. Dengan demikian, target peserta terpenuhi dan sesuai dengan perencanaan kegiatan pengabdian masyarakat ini.

3. Antusiasme peserta dalam bertanya

Peserta pelatihan cukup antusias untuk bertanya dan terlibat dalam setiap kegiatan yang diberikan. Selain menjelaskan konsep-konsep pada topik pelatihan, peserta pun diajak untuk "brainstorming" yang bertujuan untuk mengetahui pengetahuan awal mereka dan melibatkan mereka dalam setiap topik. Dengan demikian, unsur keterlibatan peserta menjadi hal penting dalam mengetahui pemahaman mereka. Setiap sesi dilakukan tanya jawab dan diskusi sehingga tidak membuat bosan peserta didik dan juga diselingi dengan kegiatan icebreaker dan game untuk meningkatkan kemampuan berbahasa Inggris mereka. Game yang diberikan adalah "what is in my pencil case", "what is in my bag" dimana permainan ini melatih peserta menebak benda-benda yang biasa tersedia di tempat pensil dan tas anak-anak. Tujuannya adalah para guru dapat mempraktekkannya di sekolah maupun di rumah untuk meningkatkan kosakata mereka. Peserta pun diajak untuk mengeja dengan benar katakata tersebut dalam permainan "spelling bee". Antusiasme peserta dalam bertanya merupakan hal penting dalam pengabdian masyarakat ini yang merupakan salah satu indikator keberhasilan kegiatan dan ketertarikan pada tema atau topik yang diusung. Selama berlangsungnya kegiatan ada delapan peserta yang bertanya tentang topik yang didiskusikan.

4. Ketercapaian kemampuan peserta dalam memahami materi 
Karena kegiatannya dilakukan selama masa pandemi dimana semua orang yang terlibat dalam kegiatan pengabdian masyarakat harus mematuhi protokol kesehatan dengan melakukan pembatasan sosial (social distancing). Maka salah satu permasalahannya adalah kami sebagai pelatih tidak bisa melakukan pelatihan dan pengamatan langsung di kelas pada guru, khususnya Mitra TK Aisyiyah 92 dalam melakukan kreativitas teknik permainan, lagu-lagu dan bercerita dan bagaimana mereka mengimplementasikannya. Namun dari lima guru yang mengajar di TK Aisyiyah, ada satu guru yang telah memberikan video rekaman pengajaran bahasa Inggris dengan mempraktekkan penggabungan antara permainan dan lagu. Ada tiga peserta yang merupakan alumni dan saat ini menjadi guru TK dan SD juga mengirimkan video rekaman dan meminta pendapat dan masukan. Hasil rekaman menunjukkan bahwa teknik permainan dan lagu yang dilakukan menunjukkan hasil yang bagus dimana telah sesuai dengan konsepnya. Walaupun demikian, dari kegiatan brainstorming dan permainan yang diberikan narasumber dan juga sesi tanya jawab mengidentifikasikan bahwa mereka memahami materi secara cukup baik.

5. Hasil evaluasi pelatihan

Evaluasi kegiatan perlu dilakukan untuk mengetahui kebermanfaatan pelatihan yang kami berikan. Selain beberapa pernyataan yang harus peserta pilih dalam bentuk pilihan ganda, peserta juga diminta untuk memberikan tanggapan, saran dan masukan terhadap kegiatan pengabdian masyarakat ini. Form evaluasi diberikan setelah kegiatan selesai. Dari 18 peserta, 15 peserta mengisi formulir yang dikirim dengan menggunakan Google form. Hasil evaluasi bisa terlihat di tabel 1 di bawah ini yang menunjukkan bahwa kegiatan pengabdian masyarakat ini berkategori baik.

Tabel 1.Evaluasi PKM

\begin{tabular}{|c|c|c|c|c|c|c|}
\hline No & Pernyataan & $\begin{array}{c}\text { Sangat } \\
\text { tidak } \\
\text { setuju }\end{array}$ & $\begin{array}{l}\text { Tidak } \\
\text { setuju }\end{array}$ & Netral & Setuju & $\begin{array}{l}\text { Sangat } \\
\text { setuju }\end{array}$ \\
\hline 1 & Kegiatan bermanfaat & & & & $\begin{array}{c}1 \\
6.7 \%\end{array}$ & $\begin{array}{c}14 \\
93.3 \%\end{array}$ \\
\hline 2 & $\begin{array}{l}\text { Materi sesuai dengan } \\
\text { kebutuhan }\end{array}$ & & & & $\begin{array}{c}5 \\
33.3 \%\end{array}$ & $\begin{array}{c}10 \\
66.7 \%\end{array}$ \\
\hline 3 & $\begin{array}{l}\text { Waktu pelaksanaan } \\
\text { mencukupi }\end{array}$ & & & $\begin{array}{c}1 \\
6.7 \%\end{array}$ & $\begin{array}{c}13 \\
86.7 \%\end{array}$ & $\begin{array}{c}1 \\
6.7 \%\end{array}$ \\
\hline 4 & $\begin{array}{l}\text { Suasana kelas } \\
\text { menyenangkan }\end{array}$ & & & $\begin{array}{c}1 \\
6.7 \%\end{array}$ & $\begin{array}{c}12 \\
80 \%\end{array}$ & $\begin{array}{c}2 \\
13.3 \%\end{array}$ \\
\hline 5 & $\begin{array}{l}\text { Narasumber memberikan } \\
\text { penjelasan secara detail }\end{array}$ & & & & $\begin{array}{c}6 \\
40 \%\end{array}$ & $\begin{array}{c}9 \\
60 \%\end{array}$ \\
\hline 6 & $\begin{array}{l}\text { Nara sumber mampu } \\
\text { mengontrol kelas }\end{array}$ & & & & $\begin{array}{c}7 \\
46.7 \%\end{array}$ & $\begin{array}{c}8 \\
53.3 \%\end{array}$ \\
\hline 7 & $\begin{array}{l}\text { Nara sumber menguasai } \\
\text { materi }\end{array}$ & & & & $\begin{array}{c}2 \\
13.3 \%\end{array}$ & $\begin{array}{c}13 \\
86.7 \%\end{array}$ \\
\hline 8 & $\begin{array}{l}\text { Peserta diberi kesempatan } \\
\text { untuk bertanya }\end{array}$ & & & & & $\begin{array}{c}15 \\
100 \%\end{array}$ \\
\hline
\end{tabular}

Tanggapan, Saran dan Masukan 


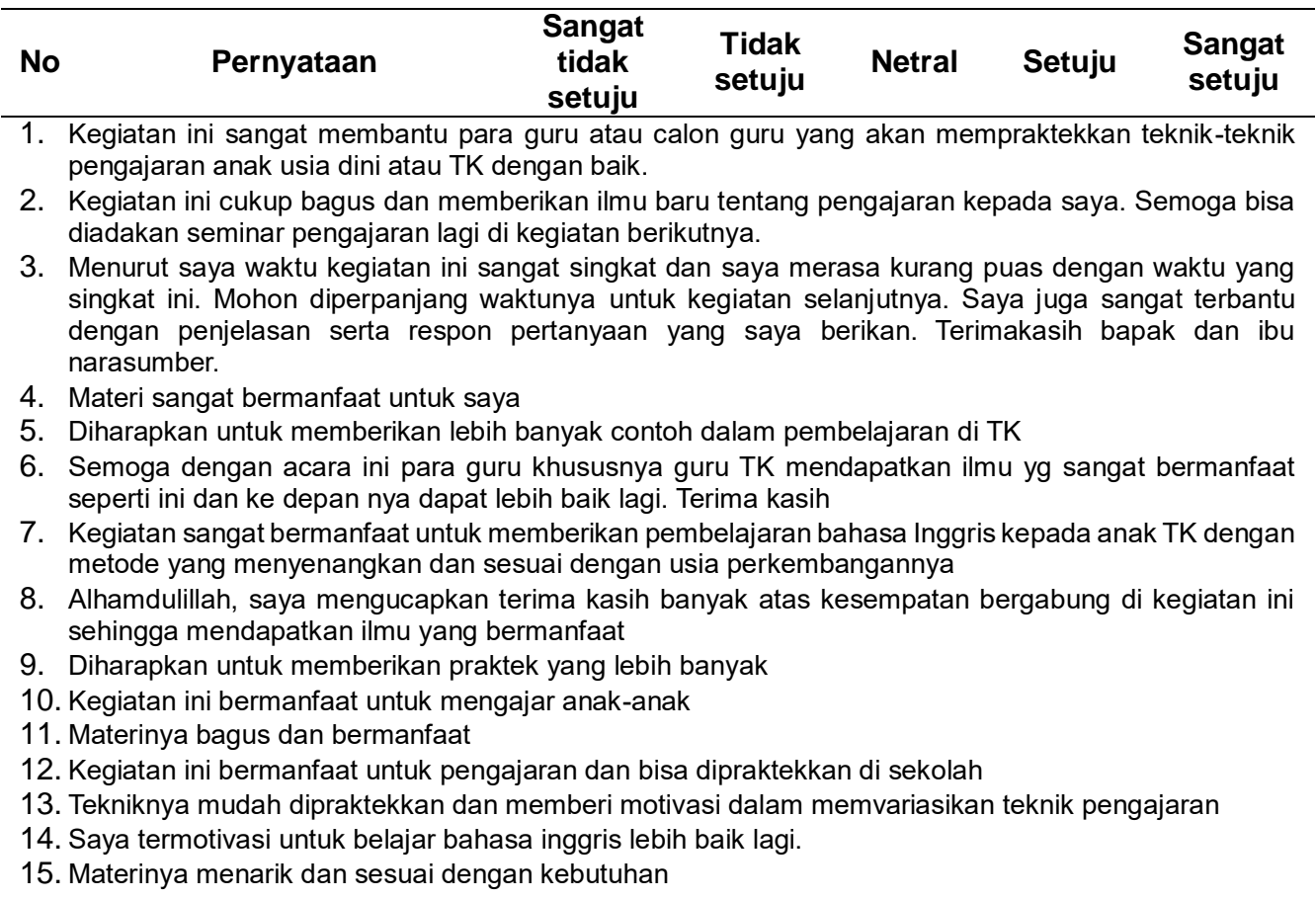

Metode Total Physical Response adalah metode pengajaran bahasa yang dikembangkan oleh James Asher yang dibangun disekitar koordinasi ucapan dan tindakan melalui teknik permainan yang menggunakan aktivitas fisik yang ditujukan untuk memudahkan dan menunjang keberhasilan proses pembelajaran (Freeman \& Anderson, 2011). Metode ini sesuai dengan karakteristik anak-anak yang lebih banyak mengunakan psikomotorik mereka dalam pembelajaran. Beberapa karakteristik anak-anak adalah mereka memahami pelajaran melalui tangan, telinga dan mata mereka; mereka senang bermain dan belajar paling baik itu adalah saat mereka bersenang-senang. Dalam metode ini, permainan menjadi lebih mendominasi anak-anak sehingga teknik permainan, lagu dan bercerita menjadi hal penting dalam proses pembelajaran. Hasil-hasil penelitian juga menunjukkan hasil positif terhadap teknik-teknik tersebut. Hasil penelitian menunjukkan bahwa bercerita menghasilkan skor tertinggi dalam meningkatkan kosakata (Albaladejo, Coyle, \& de Larios, 2018). Hasil eksperimen juga menunjukkan bahwa pendekatan bercerita untuk mengajar kosakata terbukti efektif untuk kelompok eksperimen (Kalantari \& Hashemian, 2016). Hasil penelitian eksperimen lain dalam menerapkan permainan elektronik menunjukkan bahwa ada perbedaan yang signifikan dalam memfasilitasi kompetensi bahasa Inggris di kelas taman kanak-kanak dimana post-test antara kelompok kontrol dan kelompok eksperimen yang berpihak pada kelompok eksperimen (Alnatour \& Hijazi, 2018).

Salah satu tema yang diusung adalah class routine yang bertujuan mempersiapkan anak-anak untuk kegiatan selanjutnya dan berkonsentrasi. 
Selain itu kegiatan ini akan melatih komunikasi, percaya diri dan meningkatkan kosakata serta kemampuan berbahasa Inggris. Menurut Paul (2003) class routine seringkali menjadi prasyarat yang diperlukan untuk pembelajaran yang sukses dan juga dapat memberi siswa rasa aman dan rasa memiliki. Hasil penelitian menunjukkan bahwa kegiatan class routine mampu meningkatkan kosa kata dan komunikasi anak-anak dalam bahasa Inggris (Fitriani, 2018).

Dari hasil-hasil penelitian tersebut terbukti bahwa teknik-teknik pembelajaran tersebut memberikan kontribusi positif dalam proses pembelajaran anak-anak khususnya di TK. Teknik-teknik tersebut mampu meningkatkan kosakata, dan meningkatkan keterampilan berbahasa mereka. Kegiatan class routine yang menjadi awal persiapan dalam proses selanjutnya pun mempunyai peran penting dalam peningkatan kemampuan mereka berkomunikasi dan melatih kepercayaan diri mereka sedari kecil yang perlu dibina dan dilatih.

\section{KESIMPULAN}

Pelatihan metode dan teknik pembelajaran yang difokuskan pada teknik permainan, lagu dan bercerita dalam bahasa Inggris memberikan manfaat terhadap kemampuan pedagogik peserta dan memotivasi guru dalam memvariasikan teknik pengajarannya. Selain itu, keterampilan berbicara bahasa Inggris dan kreatifitas para guru akan meningkat. Kegiatan class routine yang dilakukan di awal proses pembelajaran sebagai warming up pun akan meningkatkan kemampuan komunikasi dan kosakata bahasa Inggris mereka serta mempersiapkan mereka dalam proses pembelajaran selanjutnya. Selain itu, interaksi yang dilakukan antar anak-anak akan menumbuhkan kepercayaan diri mereka dan melatih komunikasi anak-anak, khususnya interpersonal komunikasi sejak dini yang sangat diperlukan.

Keterbatasan dalam kegiatan ini adalah belum adanya observasi langsung di tempat Mitra untuk melihat proses pembelajaran yang riil karena kondisi yang tidak memungkinkan. Sehingga dari pelatihan yang diberikan akan terlihat dampak terhadap kemajuan baik para guru maupun anak-anak. Bagi Tim PKM, perlu adanya kegiatan yang berkesinambungan dan berkelanjutan untuk meningkatkan kemampuan berkomunikasi, kemampuan dalam memvariasikan teknik-teknik pengajaran yang mampu mengakomodir gaya belajar anak-anak. Selain itu, implementasi model micro teaching juga perlu diterapkan oleh Tim PKM dengan bekerjasama dengan pihak sekolah agar mendapatkan hasil yang lebih maksimal.

\section{UCAPAN TERIMA KASIH}

Ucapan terima kasih kami sampaikan kepada LPPM Universitas Muhammadiyah Prof. DR. HAMKA yang telah memberikan dukungan finansial terhadap pelaksanaan pengabdian masyarakat ini.

\section{DAFTAR RUJUKAN}


AIShaiji, O. A. (2015). Video games promote Saudi children's English vocabulary retention. Education, 136(2), 123-132. Retrieved from https://eric.ed.gov/?id=EJ1095613

Albaladejo, S., Coyle, Y., \& de Larios, J. R. (2018). Songs, stories, and vocabulary acquisition in preschool learners of English as a foreign language.

System,

76 ,

116-128.

https://doi.org/10.1016/j.system.2018.05.002

Alnatour, A. S., \& Hijazi, D. (2018). The Impact of using electronic games on teaching English vocabulary for kindergarten students. US-China Foreign Language, 16(4), 193-205. https://doi.org/10.17265/15398080/2018.04.001

Alpine Montessori. (2017). What are kindergarten methods of teaching? Retrieved October 5, 2020, from Alpine Montessori website: https://www.alpinemontessori.com/what-are-kindergarten-methods-ofteaching/

Ashraf, H., Ghanei, F., \& Salami, M. (2014). The Impact of online games on learning English vocabulary by Iranian ( Low-intermediate) EFL learners. Procedia - Social and Behavioral Sciences, 98, 286-291. https://doi.org/10.1016/j.sbspro.2014.03.418

Bakhsh, S. A. (2016). Using games as a tool in teaching vocabulary to young learners. English Language Teaching, 9(7), 120-128. https://doi.org/10.5539/elt.v9n7p120

Barman, P., Bhattacharyya, D. D., \& Barman, P. (2015). Teaching effectiveness of teacher educators in different types of B.Ed Colleges in West Bengal, India. American Journal of Educational Research., 3(11), 1364-1377. https://doi.org/10.12691/education-3-11-5.

Colker, L. J. (2008). Twelve characteristics of effective early childhood teachers. Journal of the National Association for the Education of Young Children, 63(3), 96-106. Retrieved from https://eric.ed.gov/?id=EJ819239

Fitriani, S. (2018). Behavior contract and class routine for primary students: A case study in non-formal English institution. Jurnal Inovasi Pendidikan Dasar, 4(1), 1-12. https://doi.org/10.22236/jipd.v4i1.78

Freeman, D. L., \& Anderson, M. (2011). Techniques \& principles in language teaching (Third edit). New York: Oxford University Press.

Hwang, W.-Y., Shadiev, R., Hsu, J., Huang, Y.-M., Hsu, G.-L., \& Lin, Y.-C. (2014). Effects of storytelling to facilitate EFL speaking using Web-based multimedia system. Computer Assisted Language Learning, 29(2), 215241. https://doi.org/10.1080/09588221.2014.927367

Jassim, L. L., \& Dzakiria, H. (2019). A literature review on the impact of games on learning English vocabulary to children. International Journal of Language and Literary Studies, 1(1). Retrieved from ssrn: https://ssrn.com/abstract $=3417298$

Kalantari, F., \& Hashemian, M. (2016). A story-telling approach to teaching english to young EFL Iranian learners. English Language Teaching, 9(1), 221-234. https://doi.org/10.5539/elt.v9n1p221

Kirsch, C. (2012). Using storytelling to teach vocabulary in language lessons: 
Does it work? The Language Learning Journal, 44(1), 33-51. https://doi.org/https://doi.org/10.1080/09571736.2012.733404

Lee, S. (2012). Storytelling supported by technology: An alternative for EFL children with learning difficulties. TOJET: The Turkish Online Journal of Educational Technology, 11(3), 297-307. Retrieved from https://files.eric.ed.gov/fulltext/EJ989221.pdf

Paul, D. (2003). Teaching English to children in Asia. Hongkong: Longman Asia ELT, 2003.

Richards, J. C., \& Renandya, W. A. (2002). Methodology in language teaching: An anthology of current practice. New York: Cambridge University Press.

Wilkins, D. A. (1972). Linguistics in Language Teaching. Cambridge, MA: MIT Press.

Xiaomei, M., \& Quansheng, M. (2018). The Efficacy of song education to vevelop English proficiency for Chinese EFL majors. English Language Teaching, 11(12), 166-176. https://doi.org/10.5539/elt.v11n12p166 